\title{
Understanding How Youth Employees Use Slack
}

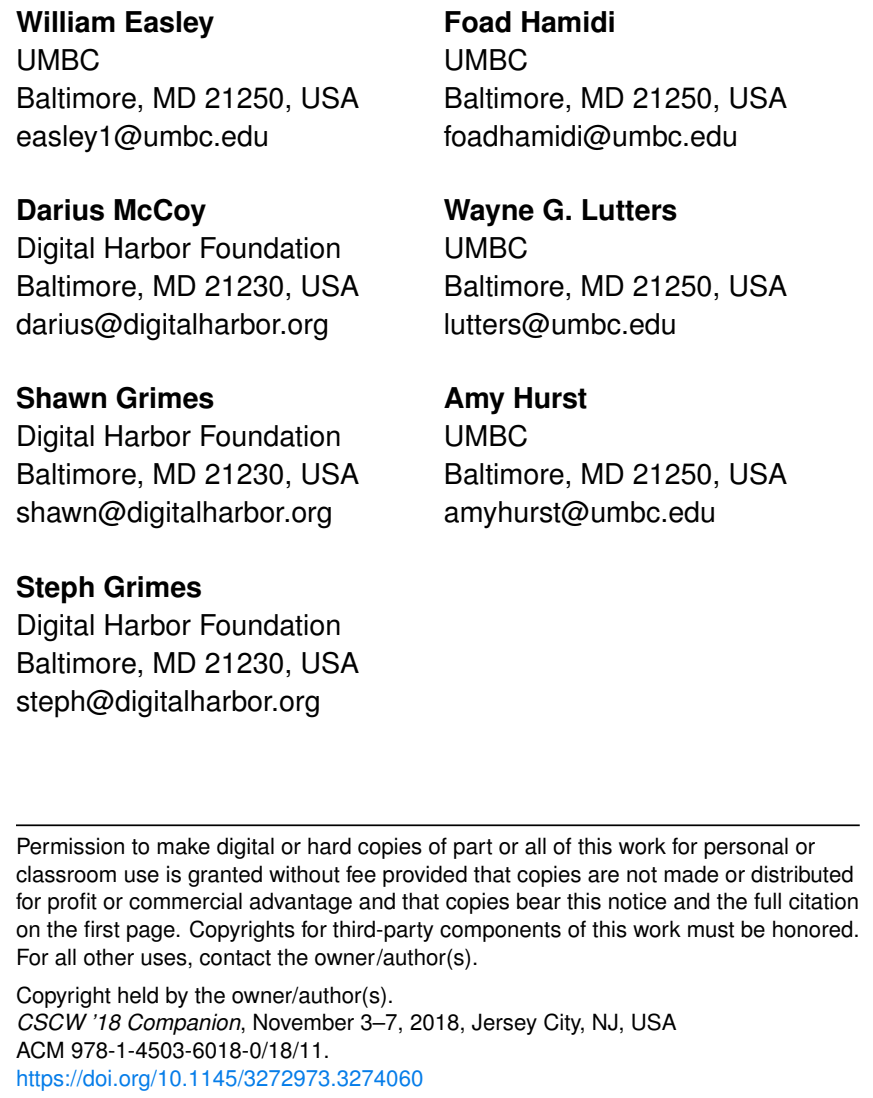

\begin{abstract}
According to the United States Census Bureau, approximately 3.1 million high school students have part time jobs. However, little is known about how youth use communication tools in professional work environments. In this paper, we present preliminary findings from an investigation into how youth employed in a 3D print shop use Slack, a popular workplace communication tool. We focus on qualitative data collected during the print shop's first year of operation. We provide insight into some of the challenges faced by youth employees while configuring Slack on their devices, and some of the ways that youth needed to adapt into being proactive and responsive in the workspace. These early findings suggest that despite being digital natives with prior experience communicating online, transitioning to Slack was not an entirely natural process. These findings will be used to inform a deeper investigation into the usage of Slack by youth working in technical jobs.
\end{abstract}

\section{Author Keywords}

Youth; Youth employment, After-school employment; Slack

\section{Introduction}

According to the United States Census Bureau, approximately 3.1 million high school students aged 16 and over have part time jobs [3]. Unlike previous generations, youth entering today's workforce have grown up in a world sur- 


\begin{tabular}{ccc}
\hline ID & Gender & Age \\
\hline P1 & F & 18 \\
P2 & M & 17 \\
P3 & M & 17 \\
P4 & M & 16 \\
P5 & M & 16 \\
P6 & F & 15 \\
P7 & F & 15 \\
P8 & F & 15 \\
\hline
\end{tabular}

Table 1: An overview of participant demographics. rounded by digital, networked technologies and have been referred to as "Digital Natives" [5] by some. There is much prior research which has investigated how teenagers use digital communication tools in the contexts where they spend most of their time. Examples include at home (e.g., [4]), in the classroom (e.g., [2]), or on a university campus (e.g., [1]). While prior work has found that employees in the modern workforce regularly utilize use a wide variety of tools - such as email, social networks, wikis, and blogs - to communicate [6], little is known about how youth use these digital tools in the workplace.

In this paper, we focus on early findings on the Slack ${ }^{1}$ usage of youth employees in a 3D print shop. Slack is accessed daily by over eight million users around the world and one of the most popular communication tools found in the workplace ${ }^{2}$. In addition to allowing users to carry out conversations in public channels or private messages, Slack has many work oriented features such as a large library of 3rd party integrations, which help to differentiate it from more mainstream communication tools (e.g, Facebook Messenger and WhatsApp). Our findings may help shed light on some of the challenges faced by youth while adjusting to new workplace communication tools.

\section{Methods}

This research is situated at the Digital Harbor Foundation ${ }^{3}$, an after-school educational and maker space for youth in Baltimore, Maryland. Our findings are based on one year of research at DHF's youth-staffed 3D print shop ${ }^{4}$. The print shop offers digital fabrication services to its local community and functions as an after-school employment experience for

\footnotetext{
${ }^{1} \mathrm{https}: / /$ slack.com/

${ }^{2} \mathrm{http}: / /$ www.businessinsider.com/slack-8-million-users-ipo-2018-5

${ }^{2} \mathrm{http}: / /$ www.businessinsider.com/
${ }^{2} \mathrm{https}: / /$ www.digitalharbor.org

${ }^{4} \mathrm{http}: / /$ printshop.digitalharbor.org
}

youth aged 14 and older. The participants in this research (Table 1) were the first cohort of youth employees at the print shop. Informed youth assent and parental consent were obtained before any data collection began.

\section{Data Sources}

The preliminary findings presented in this work are derived from two sources of data. The first is a focus group discussion with only youth employees present. This focus group was led by the first author and lasted approximately 40 minutes. While the original purpose of this focus group was to discuss experiences working independently without manager supervision, experiences configuring and using Slack became a prevalent theme. This conversation was audio recorded and then fully transcribed. We share an excerpt from this focus group discussion in our findings on configuring Slack. We focus primarily on this excerpt.

The second source is the notes taken by our research team during monthly all-employee meetings. During these meetings, print shop employees and management (from DHF's adult staff) came together for professional development/technical training activities and to discuss experiences over the past month. For this preliminary analysis, we reviewed notes from one year of meetings (12) and found that 8 included discussions about Slack. The topics discussed most frequently in these meetings are presented in our findings on engaging youth to use Slack.

Print Shop Implementation of Slack

Slack was introduced to youth employees to mirror the communication ecosystem in use by adult employees at DHF. The print shop's Slack workspace consists of three channels. The first, "staff-3Dprintshop" was the only channel for several months. It was intended for general conversation and has never been locked to a specific topic. The second, "printshop-standup," was added several months later 


\section{Excerpt From Focus Group Discussion on Configuring Timezone in Slack}

"... But when I get off of work, I don't get Geekbot until like two hours later. And when I'm doing that.. I'm still

sitting there thinking like

"hmm yeah, what was I doing today" - P6

"Wait... like you get it late?" P2

"Yeah. Sometimes I get it late ...or I get it half an hour later but then I'm in something so I don't see it until two hours later" - P6

"And that's the same with you?" - P2

". . I had that issue, but I accidentally set up the wrong time zone... So I was getting mine at like 5 AM [laughter]" $-\mathrm{P} 3$

"I get mine at 4:00 on the dot everytime... That's really weird to hear" - P2 and has been used as a structured way to support asynchronous handoffs between youth employees that work on different days. For several months, these updates were facilitated by an application called Geekbot ${ }^{5}$, which helped to automate this process. The final, "staff-ps-printerhealth," was added a year after the print shop opened to share updates on which printers are working, and which need maintenance.

\section{Early Findings on Youth Usage of Slack}

Challenges Configuring Time Zone and Notifications As mentioned previously, the print shop has a Slack channel dedicated to holding asynchronous stand-up meetings. At the end of each shift, Geekbot would send pre-defined questions to employees about their progress that day at work. Responses were then broadcast to the public standup channel.

We observed that this process did not always work as intended for all employees. Throughout the year, it was common for stand-up responses to be posted late or missed entirely. In our focus group, we found that youth had differing experiences interacting with Geekbot (see excerpt in side panel). P6 mentioned that she would frequently receive messages from Geekbot after her shift was over. She was often busy when she ultimately received the notification and would struggle to recall the details of what she did during her shift. This was surprising to P2 who had not experienced any delayed notifications, but not P3 who had previously experienced the same issue due to an incorrectly set timezone.

Later in this same conversation, P3 mentioned that they did not receive notifications when stand-up responses were posted. We note that Slack allows users to control their notification preferences based on the client type, whether the user is mentioned or messaged directly, or even on by channel.

Management Encouraging Youth to be Proactive on Slack When the print shop opened, there was an expectation that one general Slack channel would be enough and that conversations would naturally occur. However, we found that very little unprompted activity occurred. As a result, allemployee meetings regularly included discussions on how to more proactively start interactions with others. During these discussions, print shop management encouraged youth to use Slack to ask questions, get to know their new co-workers and also to share interesting articles and information with each other.

Management Encouraging Youth to be Responsive on Slack Youth were encouraged by management to promote awareness in their workplace by acknowledging messages upon receipt. Throughout the year, it was common for public announcements to receive no reaction (e.g., thumbs up) or written response; and Slack provides no read receipt. These factors lead to confusion over whether messages were received (e.g., schedule change announcements) and in some cases, over who should be held accountable for completing tasks (e.g., contacting a client). To improve responsiveness on Slack, management encouraged youth to keep posting to slack if important messages were not acknowledged, and to consider logging into Slack on personal devices (cell phone or home computer) to occasionally check for new notifications.

\section{Discussion}

All youth employees had prior experience with mainstream digital communication tools. Despite this familiarity, we observed a significant learning curve associated with Slack. 
As such, we believe that early exposure to tools such as Slack may be a valuable experience for these' employees transition into the full-time workforce.

We found that youth faced some challenges configuring their clients to receive notifications. Providing instructions, or walking through initial setup can help to avoid early problems and introduce youth to less obvious features that will help them become power users. P6s' experiences with delayed notifications and having to recall what occurred during her shift call attention to the fact that youth have other obligations outside of the workplace. As we introduce new technologies that allow youth to always stay connected to their workplace, we must remember to be support them in making healthy work-life decisions. Finally, we observed that youth were not very naturally active in initiating posts or acknowledging messages on Slack. This could be addressed through modeling or working together to define expected behaviors for the digital workspace.

\section{Conclusion and Future Work}

In this paper we present preliminary findings from our investigation into how youth employed in a 3D print shop use Slack. We identify some of the challenges encountered by youth while configuring Slack and suggest ways in which youth may need to adapt to use this tool effectively in the workplace. Our early findings suggest that despite growing up surrounded by technology, tools such as Slack may still present a learning curve. We plan to continue this investigation by interviewing print shop employees about their thoughts on using Slack, performing a thematic analysis of the content posted in all three channels, and by examining the usage statistics of the digital workspace.

\section{Acknowledgements}

This material is based on work supported by the National Science Foundation under Grant No. EEC-1623490.

\section{REFERENCES}

1. Morgan G. Ames. 2013. Managing Mobile Multitasking: The Culture of iPhones on Stanford Campus. In

Proceedings of the 2013 Conference on Computer Supported Cooperative Work (CSCW '13). ACM, New York, NY, USA, 1487-1498.

2. Dan Bouhnik and Mor Deshen. 2014. WhatsApp goes to school: Mobile instant messaging between teachers and students. Journal of Information Technology Education: Research 13, 1 (2014), 217-231.

3. Jessica Davis. 2012. School Enrollment and Work Status: 2011. American Community Survey Briefs (2012), 4.

4. Rebecca E. Grinter and Leysia Palen. 2002. Instant Messaging in Teen Life. In Proceedings of the 2002 ACM Conference on Computer Supported Cooperative Work (CSCW '02). ACM, New York, NY, USA, 21-30.

5. Marc Prensky. 2001. Digital natives, digital immigrants part 1. On the horizon 9, 5 (2001), 1-6.

6. Thea Turner, Pernilla Qvarfordt, Jacob T. Biehl, Gene Golovchinsky, and Maribeth Back. 2010. Exploring the Workplace Communication Ecology. In Proceedings of the SIGCHI Conference on Human Factors in Computing Systems (CHI '10). ACM, New York, NY, USA, 841-850. 